JEL Code M4

\title{
РАЗВИТИЕ СИСТЕМЫ НОРМАТИВНО-ПРАВОВОГО РЕГУЛИРОВАНИЯ УЧЕТА ЦЕННЫХ БУМАГ В РОССИЙСКОЙ ФЕДЕРАЦИИ
}

\author{
(c) 2019 Бурлакова Ольга Владимировна \\ доктор экономических наук, доцент кафедры бухгалтерского учета, анализа и аудита \\ Оренбургский государственный университет, Россия, Оренбург \\ E-mail: burlak4@rambler.ru
}

(C) 2019 Саушкина Виктория Владимировна

магистрант кафедры бухгалтерского учета, анализа и аудита

Оренбургский государственный университет, Россия, Оренбург

E-mail: tori56rus@mail.ru

В данной статье раскрывается необходимость дополнения нормативно-правовой базы посредством разработки нового стандарта, посвященного учету ценных бумаг. Положения и выводы, сформулированные в статье, основаны на анализе результатов научных трудов ученых и исследователей в области учета ценных бумаг на законодательном, нормативном, методическом и организационном уровнях. Новизна исследования заключается в предложении и обосновании авторами нового федерального стандарта по бухгалтерскому учету и отражению в отчетности ценных бумаг у организаций.

Ключевые слова: ценные бумаги, бухгалтерский учет, бухгалтерская финансовая отчетность, бизнес-модель.

В настоящее время ценным бумагам уделяется повышенное внимание со стороны различных организаций, что способствовало появлению их новых видов. Однако, следует отметить, что действующие нормативно-правовые документы не охватывают все существующие финансовые взаимоотношения и имеют ряд неопределенностей, связанных с процессом учета и отражением в отчетности информации о ценных бумагах.

Вопросами организации и совершенствования нормативно-правового регулирования ценных бумаг в РФ посвящены труды таких ученыхэкономистов, как Aksenova O.А. [1], Банк С.В. [2], Бурлакова О.В. [3], Гетьман В.Г. [4], Дружиловская Т.Ю. [5, 6], Дружиловская Э.С. [7], Житлухина О.Г. [8, 9], Астахова Ю.А. [10], Новичкова Н.Г. [11], Парасоцкая Н. [12, 13], Пасечник А.В. [14, 15], Плотникова О.В. [16], Савицкая Л.Ю. [17], Селезнева И.П. [18], Соломина Н.Г. [19], Фролкина Е.Н. [20], Чуваков В.Б. [21], Шишкин А.А. [22].

Цель исследования заключается в обосновании необходимости дополнения нормативноправовой базы посредством разработки нового стандарта, посвященного учету ценных бумаг. В соответствии с целью, основными задачами проводимого исследования являются: изучение уровней нормативно-правовой базы учета ценных бумаг, рассмотрение основных аспектов документов, касающихся особенностей учета ценных бумаг в российской и зарубежной практике, обоснование предложенного федерального стандарта для учета ценных бумаг. Новизна исследования заключается в предложении и обосновании авторами нового федерального стандарта по бухгалтерскому учету и отражению в отчетности ценных бумаг у организаций.

Система нормативно-правового регулирования учета ценных бумаг содержит нормативноправовые акты, каждый из которых имеет разную юридическую силу и статус. Первый уровень системы нормативно-правового регулирования представлен на рисунке 1.

В ч. 1 ст. 15 говорится, что Конституция РФ имеет высшую юридическую силу. Это говорит о том, что ни один нормативно-правовой документ, принятый на территории нашей страны не может ей противоречить. Также указанное положение определяет понятие законности потому, что она присутствует как в деятельности государства, так и юридических лиц. Правовую гарантию для осуществления инвестиционной деятельности на рынке ценных бумаг обеспечивает ст. 8 Конституции РФ. Согласно ст. 35 без решения суда невозможно никого лишить своего 


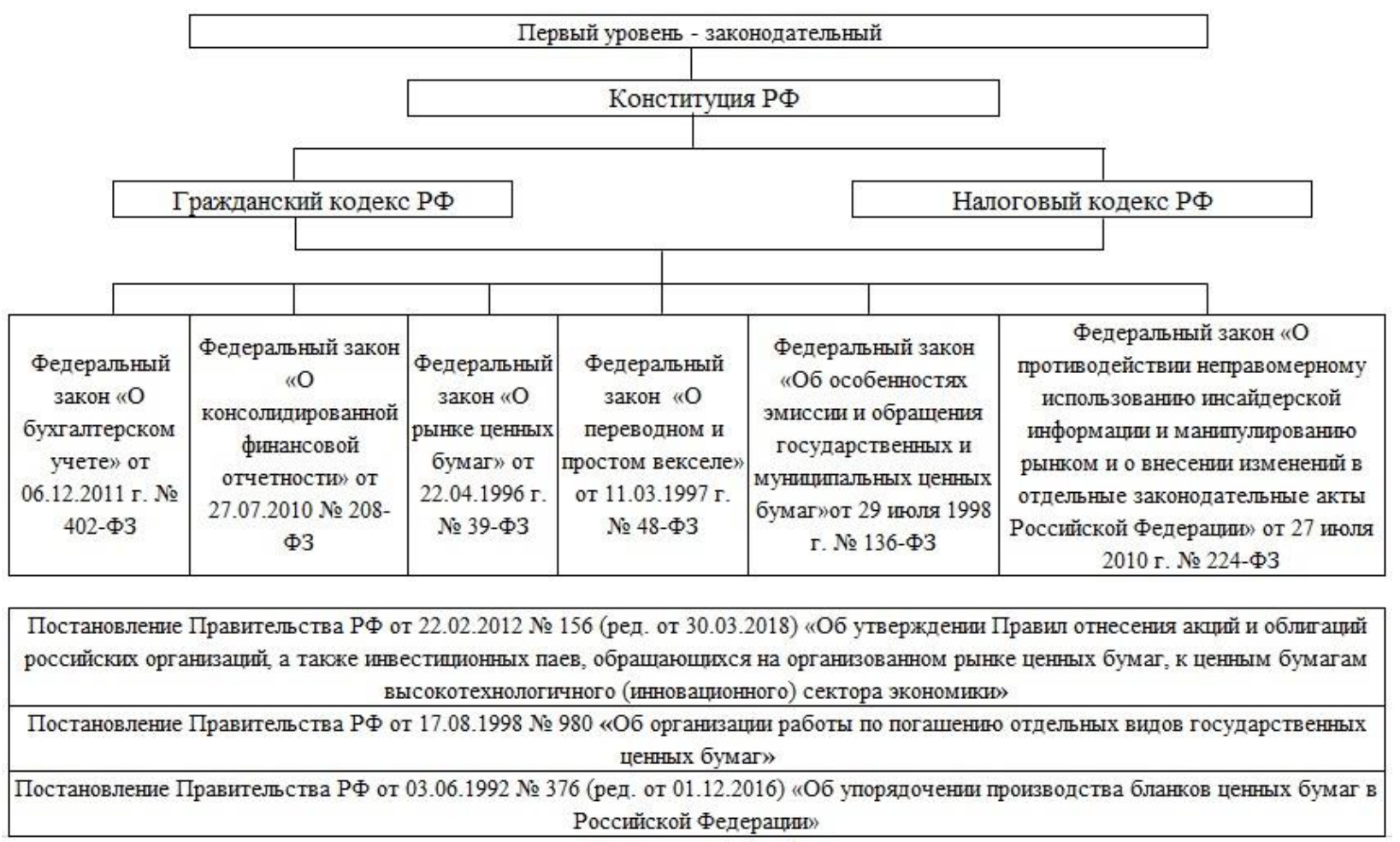

\section{Puc. 1. Первый уровень системы нормативно-правового регулирования учета} ценных бумаг в Российской Федерации

имущества.

П. 2 Постановления правительства № 156 устанавливает порядок отнесения акций, облигаций и паев к ценным бумагам высокотехнологичного (инновационного) сектора экономики, а также решения об отказе их отнесения к ценным бумагам высокотехнологичного (инновационного) сектора экономики. Постановление № 376 гласит, что производство бланков для государственных ценных бумаг осуществляется АО «Гознак». Постановление № 980 указывает, что для погашения государственных ценных бумаг, необходимо разработать специальные нормативно-правовые акты.

Видовое многообразие ценных бумаг объясняет большое количество законодательных и нормативных актов, посвященных учету ценных бумаг. Содержание федерального закона «О рынке ценных бумаг» весьма объемно, потому что в нём раскрыта взаимосвязь с другими законодательными актами, посвященным деятельности рынка ценных бумаг, а также рассмотрены многие практические вопросы, возникающие у акционерных обществ при размещении акций и других ценных бумаг. На рынке ценных бумаг защиту информации обеспечивает федеральный закон «О противодействии неправомерно- му использованию инсайдерской информации и манипулированию рынком и о внесении изменений в отдельные законодательные акты Российской Федерации».

Второй уровень системы нормативноправового регулирования представлен на рисунке 2.

В настоящее время в МСФО (IAS) 32 «Финансовые инструменты: представление» можно найти определения разных видов финансовых активов и финансовых обязательств. В указанном стандарте рассматриваются такие активы как векселя, дебиторская и кредиторская задолженность по займам и облигациям, государственные облигации, по которым установлено, что экономической выгодой, предполагающейся к получению или передаче, является финансовый актив отличный от денежных средств, а также бессрочные облигации.

Указанный стандарт уделяет особое внимание и долевым инструментам, таким, как обыкновенным акциям без права обратной продажи, привилегированным акциям, а также варрантам и колл-опционам

MCФО (IAS) 39 особое внимание уделяет требованиям к учету хеджирования, а также критериям, по которым финансовый инструмент 


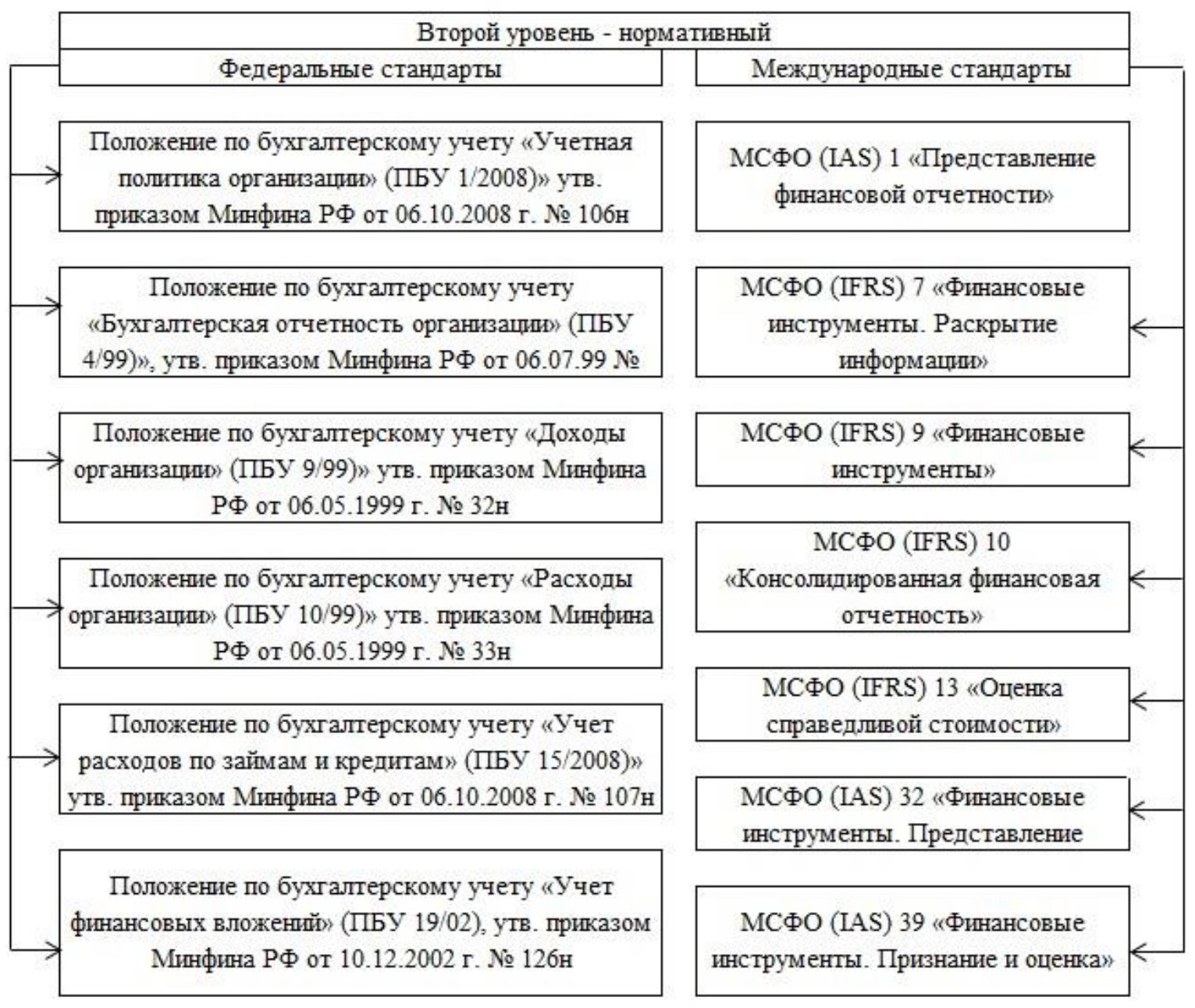

Puc. 2. Второй уровень современной системы нормативно-правового регулирования учета ценных бумаг в Российской Федерации

является частью отношений хеджирования. Необходимо заметить, что в качестве объекта хеджирования по усмотрению организации может выступать облигация, которая поддается надежной оценки. Однако важным условием при этом выступает то, что инфляция не может повлиять на другие денежные средства по такому инструменту

На сегодняшний день для учета, оценки и раскрытия информации в финансовой отчетности о ценных бумагах организации обязательно применяют четыре международных стандарта финансовой отчетности [16].

Ко второму уровню системы нормативноправового регулирования учета ценных бумаг относятся Федеральные стандарты по бухгалтерскому учету. Главным стандартом, который регулирует учет вложений в ценные бумаги, выступает ПБУ 19/02. Проанализировав содержание данного стандарта, можно увидеть целый ряд спорных вопросов. Прежде всего, это касается отсутствия определения такой категории как «ценные бумаги», что затрудняет его понимание и создает пространство для дискуссии многих ученых-экономистов [10]. Также одним из важнейших недостатков указанного стандарта является его устаревание потому, что в нём почти не рассматриваются производные финансовых инструментов. Третий недостаток связан с п. 20 ПБУ 19/02 в части корректировки стоимости финансовых вложений. Стандарт устанавливает проведение такой корректировки в конце каждого отчетного года. Однако в данном случае не учитываются интересы хозяйствующего субъекта потому, что текущая рыночная стоимость вложений в ценные бумаги (акции и др.) в течение года может существенно изменяться. И, следовательно, если организация не будет делать такую корректировку в промежуточной отчетности, то она будет содержать устаревшую информацию, 
что, в свою очередь, повлияет на принятие решений пользователей бухгалтерской финансовой отчетности [4].

Следующий недостаток, который выделяется различными учеными и относится к организациям-непрофессиональным участникам рынка ценных бумаг - это переоценка ценных бумаг. На практике данные организации для приобретения или продажи ценной бумаги будут вынуждены воспользоваться услугами брокера, что повлечет за собой дополнительные затраты на сумму которых необходимо увеличить стоимость ценной бумаги при переоценке в балансе организации.

Организации в процессе учета помимо международных стандартов должны использовать и разъяснения к ним, которые разработал комитет по МСФО. Среди них можно выделить следующие разъяснения: КРМФО (IFRIS) 2 «Доли участников в кооперативных организациях и аналогичные инструменты», разъяснение КРМФО (IFRIC) 5 «Права, связанные с участием в фондах финансирования вывода объектов из эксплуатации, восстановления окружающей среды и экологической реабилитации», разъяснение КРМФО (IFRIC) 9 «Повторный анализ встроенных производных инструментов» и разъяснение KРМФО (IFRIC) 16 «Хеджирование чистой инвестиции в иностранное подразделение». Данные разъяснения регламентируют правила составления финансовой отчетности, необходимой для принятия экономических решений пользователями, информацию, дополняющую отчетность организаций, а также описания статей, раскрытых в указанной отчетности и информацию о статьях, не подлежащих признанию.

В таблице 1 представлены предлагаемые бухгалтерские записи по отражению облигаций в учете организации-инвестора.

Мы рекомендуем к 58 счету открывать субсчета непосредственно связанные с учетом краткосрочных ценных бумаг, что будет способствовать наглядному представлению информации о них в бухгалтерской финансовой отчетности организаций. Также, по нашему мнению, вклады по договору простого товарищества не могут рассматриваться в составе финансовых вложений потому, что они осуществляются не только денежными средствами, но и другим имуществом. С этой целью нами рекомендовано вынести их на отдельный счет 54 «Вклады по договору простого товарищества».

Для решения спорных вопросов, касающихся бухгалтерского учета и отражения в отчетности, информации о ценных бумагах мы рекомендуем ввести отдельный федеральный стандарт, посвященный вложениям в ценные бумаги в России.

На основании проведенного сравнительного анализа разделов ФСБУ «Учет ценных бумаг» и ПБУ 19/02 «Учет финансовых вложений», считаем, что возникла необходимость во введении нового федерального стандарта, регламентирующим учет ценных бумаг. Данное нововведение поможет организациям, осуществляющим вложения в ценные бумаги избежать ошибок в этой области учета.

В результате, предложенный стандарт окажет влияние и на организационный уровень системы нормативно-правового регулирования. Так, например, в учетной политике организациям следует раскрывать следующую информацию:

- бизнес-модель, которую они применяют;

- классификационные признаки, которые наиболее востребованы.

Таблица 1. Предлагаемые бухгалтерские записи по отражению операций по приобретению облигаций в учете организации-инвестора

\begin{tabular}{|l|c|c|c|}
\hline \multicolumn{1}{|c|}{ Содержание хозяйственной операции } & Сумма, руб. & Дебет & Кредит \\
\hline Оприходованы облигации по фактической стоимости & 220000 & 06.1 & 51 \\
\hline $\begin{array}{l}\text { Отражена разница между номинальной стоимостью и стоимостью } \\
\text { приобретения облигаций }\end{array}$ & 5000 & 76 & 06.1 \\
\hline $\begin{array}{l}\text { Отражена сумма причитающихся процентов за минусом суммы, } \\
\text { отнесенной на счет 06.1 }\end{array}$ & 6500 & 76 & 91.2 \\
\hline Отражена сумма полученных процентов & 11500 & 51 & 76 \\
\hline $\begin{array}{l}\text { Отражена сумма причитающихся к получению денежных средств } \\
\text { по погашенным облигациям }\end{array}$ & 200000 & 76 & 91.2 \\
\hline Отражена стоимость погашенных облигаций & 200000 & 91.1 & 06.1 \\
\hline Отражена сумма, полученная по погашенным облигациям & 200000 & 51 & 76 \\
\hline
\end{tabular}




\section{Библиографический список}

1. Aksenova O.A. Evaluation of effectiveness of investments in training by financial and non-financial indicators // Economics: Yesterday, Today and Tomorrow. 2014. № 6. P. 10-24.

2. Банк С.В. Требования международных и отечественных стандартов, регулирующих учет финансовых инструментов // Международный бухгалтерский учет. 2005. № 7(79). С. 18-28.

3. Бурлакова О.В. О классификации финансовых вложений // Образование в негосударственном вузе: опыт, проблемы, перспективы (сборник научных статей).- Оренбург: ИПК ОГУ, 2008. - С. 208-214.

4. Гетьман В.Г. Совершенствование учета финансовых вложений // Международный бухгалтерский учет. 2011. № 46 (196). С. 9-13.

5. Дружиловская Т.Ю. Финансовые инструменты в бухгалтерском учете и отчетности коммерческих и некоммерческих организаций // Бухгалтерский учет в бюджетных и некоммерческих организациях. 2017. № 7. C. $2-15$.

6. Дружиловская T.Ю., Игонина Т.В. Направления реформирования учета обязательств организаций в системе российских бухгалтерских стандартов // Международный бухгалтерский учет. 2014. № 32 (326). С. 2-12.

7. Дружиловская Э.С. Оценка финансовых инструментов в Российском и международном бухгалтерском учете // Международный бухгалтерский учет. 2014. № 47. С. 26-41.

8. Житлухина О.Г. Об идентификации финансовых инструментов как совокупности финансовых фактов хозяйственной жизни в аспекте объекта бухгалтерского учета // Международный бухгалтерский учет. 2016. № 5 . С. 2-13.

9. Житлухина О.Г. Особенности понятия финансовых вложений в аспекте бухгалтерского учета и финансовой отчетности // Вестник ТГЭУ. 2007. № 1. С. 11-25.

10. Астахова Ю.А. Основные аспекты учета финансовых инструментов в международной и российской практике // Международный бухгалтерский учет. 2013. № 33 (279). С. $41-49$.

11. Новичкова Н.Г. Бухгалтерский учет изменения первоначальной стоимости финансовых вложений и резерва под снижение их стоимости // Вестник Астраханского государственного технического университета. 2004. № 3. С. 157-162.

12. Парасоцкая Н. Договор цессии: особенности учета / Н. Парасоцкая // Финансовая жизнь. 2012. № 1. С. 6-9.

13. Парасоцкая Н.Н., Шевченко А.Н. Проблемы бухгалтерского учета финансовых инструментов по российским и международным стандартам // Международный бухгалтерский учет. 2011. № 26 (176). С. 39-44.

14. Пасечник A.B. Совершенствование методики учета финансовых вложений в коммерческой организации / А.В. Пасечник // Вестник Ростовского государственного экономического университета (РИНХ). 2009. № 2. C. $280-286$.

15. Пасечник А.В. Финансовые вложения - проблема сближения национального учета и МСФО // Экономика и бизнес. Взгляд молодых: сборник материалов Всероссийской научно-практической конференции студентов и аспирантов, 30 окт. 2008 г. Челябинск: ЮУрГУ, 2009.

16. Плотникова О.В. Учет резервов в системе использования финансовых инструментов // Вестник Саратовского государственного социально-экономического университета. 2010. № 2 (29). С. 119-123.

17. Савицкая Л.Ю. Методика учета и анализа финансовых вложений в ценные бумаги: автореф. дисс. к-та экон. наук: 08.00.12. Москва, 2009. 21 с.

18. Селезнева И.П., Владимирова А.В. Развитие методики оценки и бухгалтерского учета финансовых вложений // Международный бухгалтерский учет. 2015. № 18 (360). С. 15-31.

19. Соломина Н.Г. Договор займа: изменение действующего законодательства // Вестник Омского университета. Серия «Право». 2017. № 4 (53). С. 60-64.

20. Фролкина Е.Н. Защита прав инвесторов на рынке ценных бумаг: теоретические аспекты правового регулирования // Экономика. Налоги. Право. 2011. С. 125-132.

21. Чуваков В.Б. Понятие ценных бумаг в Проекте изменений раздела 1 ГК РФ // Проблемы гражданского права и процесса. 2011. № 1(1). С. 12-22.

22. Шишкин А.А. Бухгалтерский учет операций с ценными бумагами у непрофессиональных участников рынка: автореф. дисс. к-та экон. наук: 08.00.12. Москва, 2004. 26 с. 